\title{
The more you see: spectroscopy in molecular biophysics
}

These articles are reprinted from European Biophysics Journal, Volume 39, Issue 2 where they were printed ahead of the compilation of this Special Issue in error. Original page numbers and citations are retained from the original publication date.

Eur Biophys J (2010) 39:229-239

DOI: $10.1007 / \mathrm{s} 00249-009-0527-9$

ORIGINAL PAPER

Molecular dynamics simulations reveal that AEDANS is an inert fluorescent probe for the study of membrane proteins

Werner L. Vos, Marieke Schor, Artur Baumgaertner, D. Peter Tieleman and Marcus A. Hemminga

Received: 14 May 2009/Revised: 9 July 2009

Accepted: 22 July 2009/Published online: 11 August 2009
Eur Biophys J (2010) 39:241-253

DOI: $10.1007 / \mathrm{s} 00249-009-0528-8$

ORIGINAL PAPER

Time-resolved FRET fluorescence spectroscopy of visible fluorescent protein pairs

A. J. W. G. Visser, S. P. Laptenok, N. V. Visser, A. van Hoek, D. J. S. Birch, J.-C. Brochon and J. W. Borst

Received: 20 May 2009/Revised: 9 July 2009

Accepted: 22 July 2009/Published online: 20 August 2009 